once. On June 4, two months after the excision the right eye was free from any sign of inflammation. There was a mature cataract. Examination with slit-lamp.

On July 23, four months after the removal of the left eye the patient came to the hospital and said that his eye had been red and painful for a week. It was injected, and the pupíl was small. There was some plastic material smeared on the back of the cornea. I gave him an injection of T.A.B. as a preparative to a course of M. and B. The reaction was slight. On August 6 the pupil had fully dilated with atropine, and there were only a few fine threadlike synechiae. There was still some plastic "K.P.," the iris was muddy, and the cornea steamy. August 27. No "K.P.," and only slight injection. He has had a course of N.A.B. and is much better. The M. and B. seemed to have no action on the inflammation. September 11. : Some diffuse paste-like "K.P.," slight c.c. injection. November 12. Severe pain, eye hard, and tender. Excision advised.

Here we have an inflammation almost certainly of the sympathetic type following the removal of the exciting eye after an interval of nearly four months. The socket is a good one and there is no trace of any retained uveal tissue. The eye was removed with a long bit of the optic nerve: There is no doubt that three weeks before the onset of the inflammation the eye showed no clinical signs of inflammation.

$$
\text { I am, etc., }
$$

T. HARRISON BUTLER.

BIRMINGHAM,

November 18, 1942.

\title{
UNUSUAL CASES OF CONJUNCTIVITIS
}

\section{To the Editors of THE BRITISH JOURNAL OF OPHTHALMOLOGX.}

DEAR SIRS,-According to the wish expressed by Major E. F. King, R.A.M.C., in his article "Four unusual cases of conjunctivitis" (Brit. Jl. Ophthal., Vol. XXVI, p. 467), I beg to inform you that I treated numerous cases similar to those described by the author among soldiers of the Russian Army during the last war.

The cases I am referring to were inflammations and ulcers of conjunctiva of lower fornix brought about artificially by the cauterising proceeding of chemical or thermal agencies, this has been done in order to avoid military service. Such cases were, of course unknown in Britain at the time when military service was voluntary. On the Continent, on the other hand, where military service has been compulsory, we had frequently the opportunity of noting cases 
of simulation of blindness and self-inflicted lesions of various organs, and especially of the eyes, the purpose of which actions was to avoid the military service, particularly in war-time.

I myself have seen cases of artificial ulcers of conjunctiva, artificial leucoma, traumatic cataract, chronic coujunctivitis. I have also seen cases of artificial myopia caused by a spasm of accommodation due to the use of strong concave-lensed spectacles for a long period of time or to the use of miotics.

It is conceivable that since the introduction of conscription in Britain cases of individuals trying to avoid military service might have occurred even in this country, in spite of the great patriotism of the people.

In these cases described by Major King, it is the fact that only one eye is affected, the fact of the lower fornix being the locus and scarring that make me suspect the artificial origin of the conjunctivitis.

The process of scarring of conjunctiva and symblepharon may be observed in cases of trachoma, diphtheriac conjunctivitis, pemphigus, as well as after burns. The first three causes have to be discarded, the fourth only remains as a possible explanation. The exacerbation and recidives can easily be explained by assuming that the injuries have been repeatedly inflicted in order to prolong the illness. The enlargement of the pre-auricular gland may occur as a result of a secondary infection of the injured conjunctiva with destroyed epithelium by pyogenic micro-organisms which are usually found in the conjunctival sac - in the cases described by the author, staphylococcus.

I can't, of course, be sure that my suppositions are correct, as I have not seen the cases described by Major King. In any case, if such diseases should occur among soldiers in an epidemic or even endemic form, I should advise to try and treat such cases by introducing a neutral ointment into the conjunctival sac and by isolating the eye and protecting it from further injuries by means of a tightly adhering band of the kind of those which are used in cases of gonorrhoeic conjunctivitis to protect against infection the eye which is not affected, e.g. Buller's shield. I have observed in cases which had been treated without result for several months, that the symptoms disappeared in a few days after the above described treatment has been applied.

$$
\begin{aligned}
& \text { Yours faithfully, } \\
& \text { DR. J. RUSZKowSKI, } \\
& \text { Lecturer of Ophthalmology of Polish } \\
& \text { Medical School, Edinburgh. }
\end{aligned}
$$

38. MARChMONT CRESCENT,

EDINBURGH. October 20, 1942. 